\title{
BUSINESS MODEL CANVAS SEBAGAI ALAT BANTU DALAM MENENTUKAN STRATEGI BISNIS JASA PENYEWAAN MAINAN
}

\author{
Wiwik Widiyanti ${ }^{*}$ \\ ${ }^{1}$ Jurusan Administrasi Bisnis, Universitas Bina Sarana Informatika Jakarta \\ Email: wiwik.www@bsi.ac.id \\ *penulis korespondensi
}

Masuk : 10-04-2021, revisi: 03-06-2021, diterima untuk diterbitkan : 10-06-2021

\begin{abstract}
ABSTRAK
Javasbabyboo merupakan salah satu usaha jasa penyewaan mainan yang terletak di Kebumen Jawa Tengah. Sasaran pelanggan dari Javasbabyboo saat ini adalah ibu yang mempunyai anak di bawah 5 tahun anak balita, yang mau berhemat, tidak sempat meluangkan waktu untuk memperhatikan perawatan mainan dalam jangka panjang, tidak mempunyai tempat penyimpanan khusus mainan, dan ingin memberikan variasi permainan kepada anak. Selama pandemi ini omset Javasbabyboo cenderung menurun, hal inilah yang menjadi alasan pada penelitian ini sehingga diharapkan akan mendapatkan strategi bisnis yang baru dengan menggunakan Business Model Canvas (BMC) sebagai alat bantunya. Penelitian ini termasuk dalam penelitian kualitatif, dengan menggunakan data primer pada 34 responden dari pelanggan Javasbabybo yang dipilih secara purposive serta data sekunder berupa laporan operasional tahun 2018 - 2020. Penelitian ini diawali dengan mengidentifikasi Business Model Canvas (BMC) yang sedang berjalan, kemudian menganalisa Strenght, Weakness, Opportunity, Threat (SWOT) dan yang terakhir menentukan BMC perbaikan berdasarkan analisa dari BMC yang sedang berjalan dan analisis SWOT. Diperoleh hasil penelitian bahwa BMC yang sedang berjalan sudah cukup baik, tetapi perlu adanya penambahan item pada BMC perbaikan. Penambahan item tersebut terletak pada produk baru yang disewakan dan diadakan yaitu perlengkapan ibu menyusui dan kreasi event kompetisi permainan untuk anak balita pada value proposition. Penambahan tersebut tentunya berpengaruh pada elemen-elemen yang lain sehingga pada akhirnya akan penambahan sumber penghasilan yaitu disamping dari penyewaan mainan juga dari penyewaan perlengkapan ibu menyusui dan pendaftaran event kompetisi permainan anak balita. Adapun implikasi dari penelitian ini adalah adanya BMC yang sedang berjalan disertai analisa SWOT yang tajam menghasilkan BMC perbaikan yang dapat digunakan oleh pemilik Javasbabyboo sebagai pedoman dalam menentukan kebijakan untuk meningkatkan pendapatan dari usaha ini.
\end{abstract}

Kata Kunci: Business Model Canvas, analisis SWOT, analisis rental mainan,

\begin{abstract}
Javasbabyboo is a toy rental service business located in Kebumen, Central Java. The current target customers of Javasbabyboo are mothers who have children under 5 years old, who want to save money, don't have time to pay attention to toy care in the long term, don't have a special toy storage area, and want to provide a variety of games for children. During this pandemic, the turnover of Javasbabyboo tends to decrease, this is the reason for this research so that it is hoped that it will get a new business strategy using the Business Model Canvas (BMC) as a tool. This research is included in qualitative research, using primary data on 34 respondents from Javasbabybo customers who were selected purposively as well as secondary data in the form of operational reports for 2018 2020. This research begins by identifying the ongoing Business Model Canvas (BMC), then analyzing the Strengths. , Weakness, Opportunity, Threat (SWOT) and finally determine the BMC improvement based on the analysis of the ongoing BMC and SWOT analysis. The results of the research show that the current BMC is quite good, but it is necessary to add items to the improvement BMC. The addition of these items lies in the new products that are rented and held, namely nursing mother equipment and the creation of game competition events for toddlers in the value proposition. These additions certainly affect other elements so that in the end there will be additional sources of income, apart from toy rental, also from rental of equipment for breastfeeding mothers and registration of toddler game competition events. The implication of this research is that there is an ongoing BMC accompanied by a sharp SWOT analysis resulting in improved BMC that can be used by Javasbabyboo owners as a guide in determining policies to increase income from this business..
\end{abstract}

Keywords: Business Model Canvas, SWOT analysis, toy rental analysis, 


\section{PENDAHULUAN}

\section{Latar Belakang}

Pandemic global yang melanda seluruh dunia telah membuat perubahan di semua sektor kehidupan(Amri, 2020). Sektor Usaha Mikro Kecil dan Menengah (UMKM) termasuk salah satu diantara yang terkena dampak pandemic (Rosita, 2020). Penurunan omset terjadi di semua lini UMKM (Putri, 2020). Padahal sektor UMKM dapat menjadi salah satu kunci pemulihan ekonomi (UKM, 2020). Pemberian kontribusi UMKM terhadap Produk Domestik Bruto (PDB) selalu mengalami peningkatan setiap tahunnya dimana pada tahun 2010 UMKM memberikan kontribusi terhadap PDB sebesar 3 triliun an rupiah, dan terus meningkat sampai dengan pada tahun 2018 UMKM Indonesia berkontribusi hingga sekitar 8,5 triliun rupiah (Jayani, 2020)

Adanya UMKM akan membuka lapangan kerja sehingga akan menjadi salah satu sumber penghasilan yang nantinya digunakan untuk membeli kebutuhan hidup pekerjanya, sehingga roda perekonomian akan terus berputar (Hidranto, 2020). UMKM dapat mempekerjakan karyawan sebanyak sekitar 117 juta orang dan jika dipersentasekan mencapai $97 \%$ dari total tenaga kerja Indonesia. Hingga saat ini, UMKM Indonesia sebanyak kurang lebih 64juta unit atau 99,99\% dari total unit usaha di Indonesia (Jayani, 2020).

Salah satu UMKM yang menyerap tenaga kerja adalah pada jasa penyewaan mainan. Jasa ini sangat relevan dengan kondisi pandemic saat ini, dimana ketentuan belajar daring menyebabkan anak-anak tidak bisa bersosialisasi dengan teman-temannya, sehingga para orang tua harus mempunyai kreatifitas membuat sesuatu hal menjadi menyenangkan dilakukan oleh anakanaknya terutama pada anak usia balita dan batita. Bagi orang tua yang kreatif tentunya tidak menjadi masalah, tetapi bagi orang tua yang sibuk tentunya ini menjadi permasalahan yang besar.(Tabi, 2020)

Solusi atas permasalahan tersebut adalah dengan menyediakan ragam variasi mainan yang disukai oleh anak. Namun jika membeli mainan yang dipilih untuk dijadikan solusi, tentunya membutuhkan dana yang besar karena harga mainan yang dijual di toko mainan anak tidaklah murah, sehingga ada satu solusi alternative yaitu dengan menyewa mainan anak sehingga dapat menghemat keuangan keluarga.(Octobery et al., 2020)

Ada banyak alasan untuk menggunakan jasa penyewaan mainan. Alasan utama adalah keinginan untuk berhemat, dengan menyewa mainan maka dana yang dikeluarkan akan jauh berkurang bahkan sampai dengan dibawah 50\%. Faktor kesibukan para ibu juga menjadi salah satu alasan yang menyebabkan perawatan mainan menjadi kurang maksimal, dan juga ketiadaan ruangan untuk tempat menyimpan mainan.

Jasa penyewaan mainan Javababyboo adalah sebuah jasa penyewaan permainan balita di Kota Kebumen dengan persaingan bisnis yang sudah mulai ketat, karena mulai bermunculan jasa penyewaan mainan yang sama. Pada masa pandemic ini, jumlah transaksi jasa penyewaan Javasbabyboo mengalami penurunan dan kenaikan seperti yang terlihat pada tabel 1 berikut ini.

Tabel 1. Data omset rental Javababyboo tahun 2020 Sumber: Javasbabyboo, 2020

\begin{tabular}{l|c}
\hline \multicolumn{1}{c|}{ Bulan } & Jumlah transaksi \\
\hline Januari & 50 \\
\hline Februari & 58 \\
\hline Maret & 64 \\
\hline April & 59 \\
\hline
\end{tabular}




\begin{tabular}{l|l}
\hline Mei & 62 \\
\hline Juni & 55 \\
\hline Juli & 53 \\
\hline Agustus & 50 \\
\hline September & 46 \\
\hline Oktober & 45 \\
\hline November & 46 \\
\hline Desember & 42 \\
\hline
\end{tabular}

Berdasarkan tabel 1 dapat disimpulkan bahwa omset rental Javasbabybo pada masa pandemic ini tidaklah stabil. Pada semester pertama masih terjadi kenaikan dan penurunan jumlah transaksi, namun pada semester kedua jumlah transaksi rental tersebut cenderung menurun. Hal ini tentunya menjadi ancaman untuk keberlangsungan bisnis rental Javasbabyboo.

Supaya dapat mempertahankan dan mengembangkan bisnis Javasbabyboo maka strategi bisnis harus dibuat dengan tepat. Strategi bisnis adalah upaya pengambilan kebijakan dan pedoman yang dilakukan oleh perusahaan sehingga diharapkan lebih memiliki komitmen dan tindakan yang terintegrasi yang dirancang dengan maksud membangun keunggulan dalam persaingan bisnis untuk memenuhi dan mencapai tujuan bisnis. Dengan adanya strategi bisnis, perusahaan mampu menentukan arah perusahaan dengan mengidentifikasinya dari segi pasar, pesaing, pelanggan dan lain sebagainya.(Amalia, 2020). Strategi bisnis yang ditentukan dapat menggunakan Business Model Canvas (BMC) sebagai alat bantunya, dikarenakan di dalam BMC terdapat elemen-elemen yang membuat diskusi menjadi fokus dalam penentuan strategi bisnis.

Berdasarkan pemaparan tersebut diatas, maka penelitian ini bertujuan menganalisis bisnis model canvas sebagai alat bantu dalam menentukan strategi bisnis pada jasa penyewaan Javasbabyboo dalam masa pandemic sekaligus menganalisis kekuatan (strenght), kelemahan (weakness), peluang (opportunity), dan Ancaman (threat) atau sering disebut dengan analisa SWOT guna mendapatkan BMC perbaikan. Hal ini sekaligus sebagai novelty dari penelitian ini dimana belum ada penelitian yang membahas jasa penyewaan mainan dari sisi bisnis model canvas dalam masa pandemi.

\section{Kajian Teori}

\section{Business Model Canvas (BMC)}

Penentuan strategi bisnis yang tepat membutuhkan beberapa alat bantu, salah satunya adalah berupa BMC. BMC merupakan penggambaran penjelasan suatu organisasi mengenai penciptaan, penyampaian dan penerapan suatu nilai (Osterwalder \& Pigneur, 2010). Bisnis skala kecil atau UMKM dapat menggunakan model bisnis kanvas sebagai alat bantu untuk menentukan strategi dalam menghadapi persaingan (Umar et al., 2018). Adapun tujuan dari pembuatan BMC adalah sebagai alat bantu pada UMKM dalam perancangan perencanaan ketika proses bisnis berlangsung dan penetapan serta pemvalidasian yang merupakan poin penting dalam bisnis. Poin tersebut dapat berupa sumber daya, pendapatan, semua aktivitas yang akan dilangsungkan, semua hubungan yang terjalin dengan pihak terkait serta pengeluaran dari UMKM tersebut (LinovHR, 2020).

BMC itu sendiri berupa pemetaan 9 bagian utama yaitu Customer Segmen, Value propositions, Channel, Customer relationships, Revenue Streams, Key Resources, Key Activities, Key Partnerships, Cost Structure (Crotty et al., 2018). Pemetaan ini dimaksudkan untuk mengelompokkan hal-hal yang penting sehingga ketika akan menentukan strategi bisnis yang tepat, para pelaku usaha akan focus pada poin-poin tersebut (Global Leadership Center, 2020) 
Customer segmen membahas mengenai pihak yang menggunakan jasa/produk yang ditawarkan. Hal ini bisa dilihat dari segmentasi konsumen yang dibidik. Sedangkan value propositions membahas mengenai poin-poin dari keunikan jasa/produk. Keunikan ini harus menonjol dari pesaingnya, dan harus bisa memecahkan masalah serta memenuhi keinginan konsumen. Adapun channel membahas mengenai bagaimana suatu perusahaan berkomunikasi dengan customer segment dalam penyampaian value proposition, yang membahas mengenai startegi dalam meningkatkan kesadaran, kemudahan penilaian oleh pelanggan, memberikan bantuan kepada pelanggan dalam pembelian produk atau jasanya. Berikutnya adalah customer relationships dimana pada elemen ini pelaku usaha memberikan nilai tambah pada hubungan dengan pelanggan baik pelanggan lama maupun baru. Selain itu Revenue Streams juga disertakan dalam elemen BMC, yaitu membahas mengenai transaksi apa saja untuk memperoleh pendapatan dari setiap customer segment.

Sementara itu Key Resources merupakan poin-poin yang memberi gambaran semua asset yang mendorong berhasilnya pengoperasioan model bisnis, misalnya berupa aset fisik, aset sumber daya manusia, aset intelektual, teknologi, dsb. Elemen selanjutnya adalah Key Activities yang merupakan poin dari kegiatan yang menentukan suatu model bisnis..Key Partnerships adalah salah satu elemen yang membahas mengenai siapa mitra yang diajak kerja sma dalam pengoperasian bisnis. Elemen terakhir adalah cost structure yaitu poin-poin yang menggambar keseluruhan biaya yang dikeluarkan oleh pelaku usaha tersebut (Osterwalder \& Pigneur, 2010)

\section{Analisa Strength, Weakness, Opportunities, Threats (SWOT)}

BMC juga berkaitan erat dengan analisa Strength, Weakness, Opportunities, Threats (SWOT) dimana ini merupakan analisa berupa evaluasi pada semua kekuatan dan kelemahan dari factor internal usaha selain itu juga mengevaluasi peluang, dan ancaman dari factor eksternal usaha (Kotler \& Keller, 2016)

Analisa pada faktor internal ada dua, yaitu kekuatan (strenght) dan kelemahan (weakness). Kekuatan merupakan faktor yang mengemukakan nilai positif dari sisi internal perusahaan. Sedangkan kelemahan adalah faktor negatif yang dapat mengurangi nilai kekuatan dari internal perusahaan. Adapun faktor eksternal perusahaan juga mempunyai dua faktor yaitu peluang (opportunities) dan ancaman (threats). Peluang merupakan faktor eksternal yang cenderung memberikan kontribusi pada suksesnya bisnis pada perusahaan, sedangkan ancaman termasuk dalam faktor eksternal di luar kendali pelaku usaha sehingga harus tetap dipertimbangkan untuk proses antisipasinya agar tidak menggagu jalannya perusahaan menuju sukses.(Puspitasari et al., 2019)

Sudah banyak penelitian mengenai pengembangan strategi dan pada umumnya metode yang digunakan adalah dengan menggunakan matriks SWOT dan BMC (Hartatik \& Baroto, 2017). Sementara itu penelitian dengan obyek penelitian Garasi Kampus menggunakan BMC sebagai alat bantu dalam pengembangan bisnisnya dimana analisis SWOT juga digunakan untuk merancang strategi bisnis. Hasil dari penelitian tersebut didapat beberapa temuan yang memerlukan penyesuaian. Penyesuaian tersebut ada pada elemen value proposition yang dapat dikembangkan menjadi private mobility management. Selain itu penyesuaian dilakukan pada penambahan elemen channel, customer relationship, customer segment. (Puspitasari et al., 2019) 
Masih pada penelitian dengan obyek yang sama yaitu rental mobil, penelitian ini lebih membahas pada strategi perluasan bisnis rental mobil Wiralodra 27 menggunakan pendekatan model bisnis kanvas dengan hasil penelitian yang menunjukkan rekomendasi untuk perbaikan pada seluruh elemen kunci BMC. Adapun prioritas utama perbaikan BMC ada di elemen Key Partnership, customer segment, Revenue Stream terkait faktor risiko utama bisnis. Prioritas kedua adalah pada beberapa elemen yaitu value propositions, channel, customer relationship, Key Resources, Key Activities, cost structure. (Agustiadi et al., 2018)

\section{Rumusan Masalah}

Adapun rumusan masalah dalam penelitian ini adalah:

a. Bagaimana identifikasi bisnis model canvas yang sedang berjalan pada jasa penyewaan mainan Javasbabyboo

b. Bagaimana analisa SWOT pada jasa penyewaan mainan Javasbabyboo

c. Bagaimana perumusan bisnis model canvas perbaikan pada jasa penyewaan mainan Javasbabyboo

\section{METODE PENELITIAN}

Penelitian ini dilakukan pada jasa penyewaan mainan Javasbabyboo yang terletak di pusat kota Kebumen, Jawa Tengah. Penelitian ini termasuk dalam bentuk penelitian kualitatif dengan metode analisis menggunakan deskriptif kualitatif yaitu menganalisis data hasil dari gambaran dan ringkasan berbagai situasi dan kondisi dari berbagai data yang dikumpulkan dengan menggunakan teknik wawacara atau pengamatan terkait dengan masalah yang diteliti (Winartha, 2006).

Data primer dalam penelitian ini diambil dari pemilik jasa penyewaan mainan Javasbabyboo, selain itu data primer juga diambil dari pelanggan jasa penyewaan sebagai responden yang dipilih secara purposive sebanyak 34 responden. Data sekunder diambil dari dokumen laporan operasional perusahaan $2018-2020$.

Observasi, wawancara dan studi pustaka adalah teknik pengumpulan yg digunakan pada penelitian ini. Cara observasi yaitu dengan mengamati proses kegiatan pada jasa penyewaan mainan Javasbabyboo, Sedangkan wawancara bertujuan untuk menggali informasi yang berkaitan dengan proses kegiatan pada jasa penyewaan Javasbabyboo dengan mewawancarai 2 responden internal yang terdiri dari 1 pemilik usaha dan 1 karyawan, serta 34 responden eksternal yang merupakan pelanggan jasa penyewaan Javasbabyboo. Pemilihan responden eksternal menggunakan metode convenience sampling. Peneliti melakukan Focus Group Discussion (FGD) bersama pemilik usaha dan seorang pakar bisnis sehingga diskusi lebih terarah dan diharapkan dapat menemukan rumusan perbaikan business model canvas. Studi pustaka juga dilakukan dengan mendapatkan literature dari web, buku, dan jurnal, selain itu juga dari laporan operasional perusahaan.

Ada tiga tahapan dalam pengolahan data dan analisa pada penelitian ini, yaitu: identifikasi BMC yang sedang berjalan, analisis SWOT, dan perumusan BMC perbaikan. Perumusan BMC yang sedang berjalan dilakukan dengan menganalis data dan informasi yang didapat, kemudian peneliti menganalisis SWOT dengan merumuskan kelemahan dan kekuatan, ancaman dan peluang masing-masing elemen pada BMC. Setelah mengidentifikasi BMC yang sedang berjalan, BMC tersebut dievaluasi dengan menggunakan analisis SWOT dan kemudian dirumuskanlah BMC perbaikan 


\section{HASIL DAN PEMBAHASAN}

\section{Identifikasi BMC yang sedang berjalan}

Identifikasi BMC yang sedang berjalan pada jasa penyewaan mainan Javasbabyboo dimulai dengan mengidentifikasi elemen-elemen BMC sehingga diketahui elemen mana yang sudah maksimal dan belum maksimal pada kegiatan bisnis yang sedang berjalan.

a. Value propositions: Javasbabybooo adalah sebuah usaha jasa penyewaan mainan terpercaya yang menyediakan unit mainan dengan beragam jenis dengan harga bersaing sehingga dapat menghemat budget untuk pembelian unit mainan sekaligus dapat membantu para ibu agar tidak perlu kuatir dalam hal perawatan dan penyimpanan mainan dalam jangka panjang.

b. Customer Segment. Ada dua prioritas utama dalam segmentasi konsumen yang dibidik oleh jasa penyewaan mainan Javasbabyboo saat ini tentunya yang utama adalah anak balita sesuai unit mainan yang disediakan untuk disewakan, dan yang tidak kalah penting adalah para ibu yang mempunyai karakter mau berhemat, kesulitan mengatur waktu untuk merawat unit mainan, tidak mempunyai ruangan yang cukup untuk menyimpan mainan serta para ibu yang konsen dengan variasi ragam mainan untuk anaknya.

c. Customer Relationship. Hubungan yang dibangun oleh jasa penyewaan mainan Javasbabyboo terhadap konsumen termasuk dalam kategori personal assistance dimana ada sales yang melayani pelanggan. Hubungan yang terjadi tentunya digunakan untuk jangka panjang (long term).

d. Channels. Berdasarkan hasil penelitian, Javasbabyboo memiliki dua kategori channels, yaitu dengan menginformasikan kepada pelanggan mengenai value proposition melalui social media seperti whatsapp dan facebook pribadi (awareness), dan menawarkan langsung kepada pelanggan (direct)

e. Key Activities. Pada elemen ini dibahas mengenai aktivitas yang dilakukan oleh pelaku usaha untuk menjalankan bisnisnya, mempertahankan pelanggan dan menarik pelanggan yang baru. Berdasarkan hasil observasi dan wawancara terstruktur yang dilakukan dalam penelitian ini Key activities jasa penyewaan mainan Javasbabyboo adalah dengan memilih dan membeli unit mainan dengan varian yang menarik dan uptodate untuk dijadikan persediaan stok unit mainan yang disewakan (problem solving)

f. Key Resources. Elemen ini membahas mengenai sumber daya, dimana ada dua sifat sumberdaya yaitu sumberdaya fisik (tangible) dan sumberdaya non fisik (intangible). Sumberdaya fisik artinya yang dapat dilihat dan diukur langsung seperti bangunan gedung, ruko, peralatan sedangkan sumber daya non fisik artinya yang tidak dapat dilihat seperti intelektual, dsb. Hasil analisis key resources dalam penelitian ini yang berbentuk fisik meliputi ruko, unit mainan, data base pelanggan dan supplier, karyawan yang dapat diandalkan. Sedangkan key resources yang berbentuk intellectual meliputi pengetahuan tentang mainan dan psikologi anak (intagible resources),

g. Key Partnership. Berdasarkan hasil penelitian pada jasa penyewaan mainan Javasbabyboo didapatkan adalah grosir mainan, toko alat pembersih mainan, jaringan anggota Javasbabyboo, sesama pebisnis jasa penyewaan mainan.

h. Cost Stucture. Membahas mengenai seluruh biaya pengoperasian bisnis. Struktur biaya yang dikeluarkan oleh pelaku usaha jasa penyewaan mainan Javasbabyboo ini adalah pembelian unit mainan yang baru, maintenance unit mainan, pembayaran gaji karyawan, biaya sewa ruko, biaya pemasaran, dan tagihan listrik telpon serta internet.

i. Revenue Stream. Pemasukan utama dari jasa penyewaan mainan Javasbabyboo bersumber dari transaksi penyewaan mainan. 


\begin{tabular}{|c|c|c|c|c|c|}
\hline \multirow[t]{2}{*}{$\begin{array}{l}\text { Key } \\
\text { Partners } \\
\text { - Grosir mainan } \\
\text { - Toko alat pembersih } \\
\text { mainan } \\
\text { - Jaringan anggota } \\
\text { Javasbabyboo } \\
\text { - Sesama pebisnis } \\
\text { Jasa penyewaan mainan }\end{array}$} & $\begin{array}{l}\text { Key } \\
\text { Activities } \\
\text { Problem Solving : } \\
\text { memilih dan membeli } \\
\text { unit mainan dengan } \\
\text { varian yang menarik } \\
\text { dan uptodate untuk } \\
\text { dijadikan persediaan } \\
\text { stok unit mainan yang } \\
\text { disewakan }\end{array}$ & \multirow{2}{*}{\multicolumn{2}{|c|}{$\begin{array}{l}\text { Value } \\
\text { Proposition } \\
\text { Javasbabybooo adalah } \\
\text { sebuah usaha jasa } \\
\text { penyewaan mainan } \\
\text { terpercaya yang } \\
\text { menyediakan unit } \\
\text { mainan dengan } \\
\text { beragam jenis dengan } \\
\text { harga bersaing sehingga } \\
\text { dapat menghemat } \\
\text { budget untuk pembelian } \\
\text { unit mainan sekaligus } \\
\text { dapat membantu para } \\
\text { ibu agar tidak perlu } \\
\text { kuatir dalam hal } \\
\text { perawatan dan } \\
\text { penyimpanan mainan } \\
\text { dalam jangka panjang. }\end{array}$}} & $\begin{array}{l}\text { Customer } \\
\text { Relationships } \\
\qquad \text { Personal assist }\end{array}$ & \multirow{2}{*}{$\begin{array}{l}\text { Customer } \\
\text { Segments } \\
\text { nferioritas 1: Ibu yang } \\
\text { mempunyai anak di } \\
\text { bawah } 5 \text { tahunAnak } \\
\text { balita, yang mau } \\
\text { berhemat, tidak sempat } \\
\text { meluangkan waktu } \\
\text { untuk memperhatikan } \\
\text { perawatan mainan } \\
\text { dalam jangka panjang, } \\
\text { tidak mempunyai } \\
\text { tempat penyimpanan } \\
\text { khusus mainan, ingin } \\
\text { memberikan variasi } \\
\text { permainan kepada anak } \\
\text { Prioritas 2: Anak yang } \\
\text { berusia dibawah } 5 \\
\text { tahun. }\end{array}$} \\
\hline & $\begin{array}{l}\text { Key } \\
\text { Resources } \\
\text { - tangible: ruko, unit } \\
\text { mainan, database } \\
\text { pelanggan, } \\
\text { - intangible: } \\
\text { pengetahuan tentang } \\
\text { mainan dan psikologi } \\
\text { anak. }\end{array}$ & & & 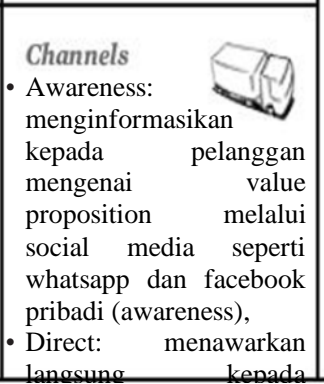 & \\
\hline \multicolumn{3}{|c|}{$\begin{array}{l}\text { Cost } \\
\text { Structure } \\
\text { - Pembelian unit mainan yang baru, maintenance unit mainan, } \\
\text { pembayaran gaji karyawan, sewa ruko, pemasaran, tagihan } \\
\text { listrik, telepon dan internet }\end{array}$} & \multicolumn{2}{|c|}{$\begin{array}{l}\text { Revenue } \\
\text { Streams } \\
\text { - Transaksi penyewaan unit mainan }\end{array}$} & \\
\hline
\end{tabular}

Gambar 1. BMC yang sedang berjalan

Sumber: Data yang diolah 2020

\section{Analisa SWOT}

Pemahaman atas faktor-faktor yang mempengaruhi keberhasilan suatu usaha baik internal maupun eksternal sangat perlu dilakukan. Oleh karena itu metode analisa SWOT dibutuhkan untuk menggali kekuatan, kelemahan, peluang dan ancaman sehingga perumusan strategi bisnis mendaji maksimal. Analisa SWOT pada jasa penyewaan mainan Javasbabyboo ini dapat dilihat pada tabel 2 berikut ini.

Tabel 2. Analisa SWOT Jasa Penyewaan Mainan Javasbabyboo

Sumber: Data yang diolah, 2020

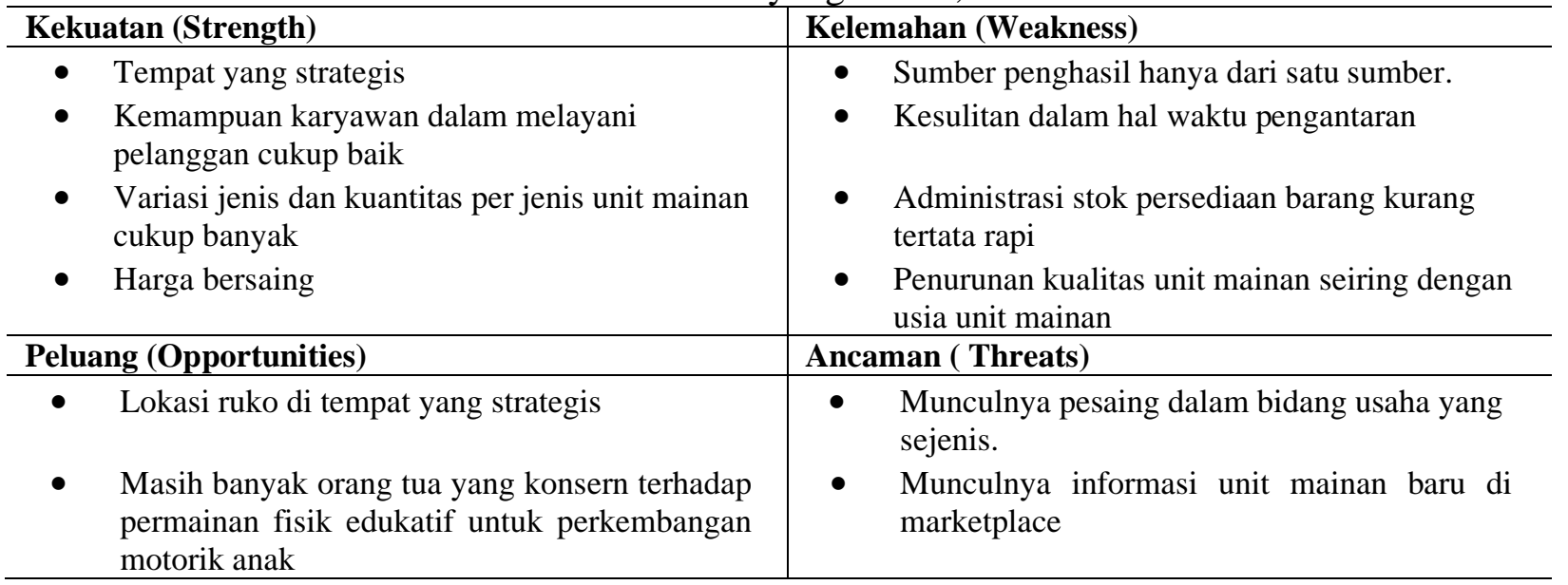


- Masih banyak orang tua yang berkeinginan untuk berhemat

- Masih banyak orang tua yang tidak mempunyai waktu untuk merawat unit mainan yang dimiliki

- Ketertarikan anak balita terhadap permainan fisik masik cukup tinggi.

- Masih banyak orang tua yang tidak mempunyai ruangan khusus untuk menyimpan mainan

Berdasarkan diskusi FGD menghasilkan poin-poin SWOT pada tabel 2 yang terdiri dari dua faktor yaitu faktor internal yang membahas kekuatan dan kelemahan dari dalam jasa penyewaan mainan Javasbabyboo, sedangkan faktor eksternal membahas peluang dan ancaman dari luar jasa penyewaan mainan Javasbabyboo.

Kekuatan utama Javasbabyboo terletak di tempat yang strategis sehingga memudahkan mobilitas dari aktifitas pelayanan. Sejalan dengan itu Javasbabyboo juga mempunyai seorang karyawan yang handal dalam pelayanan sehingga membuat pelanggan puas. Harga yang bersaing dari pesaingnya membuat Javasbabyboo lebih unggul dari yang lain. Tidak hanya itu, Javasbabyboo juga memiliki jenis mainan yang cukup variatif sehingga pelanggan mempunyai banyak pilihan. Jumlah unit mainanpun tidak hanya 1 unit untuk 1 jenis mainan, melainkan ada lebih dari 1 unit sehingga pelanggan lain bisa meminjam jenis mainan yang sama.

Adapun kelemahan Javasbabyboo adalah jumlah karyawan yang hanya satu orang membuat Javasbabyboo harus mengatur waktu pengantaran sehingga tidak bisa langsung diantar saat transaksi penyewaan dilakukan. Seringkali menghadapi kendala salah dalam melihat stok sehingga pelanggan merasa kecewa ketika karyawan meralat ketersediaan unit mainan yang dipilihnya. Hal ini akibat dari proses administrasi persediaan stok barang yang kurang tertata rapi. Semua jenis mainan tentunya memiliki penurunan kualitas seiring dengan berjalannya waktu, sehingga hal ini juga menjadi kelemahan dari Javasbabyboo. Selain itu, kelemahan lainnya adalah Javasbabyboo hanya memiliki satu sumber pendapatan yaitu dengan penyewaan mainan saja.

Pada faktor eksternal, ada beberapa peluang Javasbabyboo yang dapat dikembangkan. Peluang pertama adalah letak lokasi ruko yang strategis sehingga Javasbabyboo banyak diketahui orang yang lalu lalang di depan ruko. Selanjutnya unit mainan yang disewakan sangat mendukung perkembangan motorik anak, sehingga banyak orangtua yang menyukainya. Sebagian besar orangtua kurang mampu dalam merawat dan menyimpan mainan sehingga dapat memilih Javasbabybooo sebagai solusinya. Meskipun banyak game online ada di gawai, tetapi fitrah anak balita adalah lebih tertarik dengan unit mainan fisik sehingga variasi jenis mainan sangat dibutuhkan. Keterbatasan anggaran orangtua untuk membeli berbagai jenis mainan menjadi peluang bagi Javasbabyboo untuk menarik minat orangtua pada jasa penyewaan mainan tersebut. Hal ini juga dapat menjadi solusi ketika orangtua ingin berhemat.

Adapun ancaman bagi Javasbabyboo dimulai dari munculnya pesaing pada bidang usaha yang sama yakni jasa penyewaan mainan, sehingga jika tidak dikelola dengan baik maka ada kemungkinan pelanggan akan berpaling kepada jasa penyewaan mainan milik pesaing. Adanya marketplace yang banyak menjual mainan dengan harga rendah juga merupakan ancaman tersendiri bagi Javasbabyboo, sehingga pelanggan bisa membeli unit mainan sendiri. Selanjutnya 
promosi game online pada gawai yang sangat menarik dan gencar dapat menyebabkan anak-anak lebih memilih bermain game online.

Strategi yang dihasilkan untuk memaksimalkan kekuatan Javasbabyboo adalah dengan menggali informasi mainan yang sedang trending sehingga variasi unit mainan semakin bertambah dan semakin menarik. Selanjutnya strategi untuk meminimalkan kelemahan Javasbabyboo adalah dengan menambah karyawan baru sehingga lebih mudah dalam pembagian tugas pengantaran. Solusi lain dalam mengatasi masalah pengantaran dapat pula dengan melakukan kolaborasi bersama ekspedisi ojek online jika mainan tersebut kecil volumenya. Selain itu dengan menyempurnakan proses adminstrasi persediaan barang dengan menggunakan aplikasi stok persediaan produk yang ada di playstore. Strategi meminimalkan kelemahan juga dapat dengan menambah sumber penghasilan baru misalnya dengan mengadakan even kompetisi dan menambah produk yang disewakan seperti penyewaan perlengkapan ibu menyusui. Perlengkapan ibu menyusui ini disarankan juga disewakan mengingat harganya yang cukup mahal dan digunakan hanya sebentar saja.

Sementara itu, strategi dalam memaksimalkan peluang adalah dengan mendesain ruko semenarik mungkin agar calon pelanggan yang melewati ruko penyewaan mainan tersebut tertarik untuk datang ke ruko mengingat lokasi ruko terletak di tempat yang strategis. Masih banyaknya orangtua yang lebih memperhatikan kebutuhan perkembangan motorik anak menjadi peluang yang sangat besar. Hal ini dapat dimaksimalkan dengan mengadakan event kompetisi misalnya lomba merakit robot, lomba membuat sesuatu dengan block, dsb. Hal ini tentunya akan membuat anak-anak tertarik untuk mengikuti lomba tersebut. Sementara itu strategi memaksimalkan peluang yang lain yaitu dengan menyediakan perlengkapan ibu menyusui untuk disewakan, sehingga solusi dari keinginan untuk berhemat para ibu menyusui dapat terselesaikan. Adapun strategi meminimalkan ancaman pada jasa penyewaan Javasbabyboo dari sisi munculnya pesaing dalam bidang usaha yang sejenis dapat dilakukan dengan meningkatkan pelayanan sehingga pelanggan nyaman dan akhirnya akan menimbulkan loyalitas terhadap Javasbabyboo.

\section{BMC Perbaikan}

Berdasarkan hasil FGD dengan mempertimbangkan BMC yang sedang berjalan dan analisa SWOT, maka dihasilkanlah BMC perbaikan dengan tujuan agar Javasbabyboo mengalami perkembangan yang signifikan sehingga dapat memperoleh pendapatan yang tinggi. Berikut ini adalah identifikasi BMC perbaikan.

a. Value propositions. Pada BMC perbaikan ada penambahan value proposition yaitu dengan menyediakan perlengkapan ibu menyusui, sehingga unit yang disewakan menjadi lebih luas lagi. Penambahan yang lain adalah dengan diadakannya event kompetisi untuk anak sehingga akan menjadi pengalaman baru bagi anak balita tersebut. Sesuai dengan strategi SWOT untuk meminimalisir kelemahan maka ada perbaikan rule dalam penyewaan mainan dan perlengkapan ibu menyusui.

b. Customer Segment. Segmentasi konsumen yang dibidik oleh jasa penyewaan mainan Javasbabyboo saat ini masih sama dengan BMC yang sedang berjalan hanya ada penambahan segmen yaitu para ibu yang menginginkan anak mereka memiliki pengalaman berkompetisi misalnya dengan mengikuti kompetisi merakit permainan robot, permainan block, dsb. Hal ini sesuai dengan strategi SWOT untuk meminimalkan kelemahan. Penambahan lain adalah dengan prioritas 3 yaitu ibu menyusui.

c. Customer Relationship. Hubungan dengan pelanggan masih sama dengan BMC yang sedang berjalan hanya ada penambahan menggunakan community atau menciptakan komunitas ibu yang mempunyai anak balita dan komunitas ibu menyusui sehingga ada interaksi saling 
sharing pengalaman atau informasi yang berguna. Dengan adanya komunitas tersebut maka Javasbabyboo dapat mempromosikan jasa penyewaan mainan dan perlengkapan ibu menyusui secara tepat sasaran.

d. Channels. Pada elemen ini masih sama dengan BMC yang sedang berjalan dan tidak ada penambahan.

e. Key Activities. Penambahan yang ada pada elemen ini adalah dengan mengadakan even kompetisi yang menarik bagi anak balita.

f. Key Resources. Dengan adanya penambahan pada key activities maka pada elemen ini ada penambahan sumberdaya terutama pada bagian permodalan dan karyawan.

g. Key Partnership. Penambahan pada elemen ini mengacu pada elemen-elemen sebelumnya dimana ada penambahan produk yang disewakan yaitu perlengkapan ibu menyusui sehingga key partnership yang ditambahkan adalah toko grosir dan toko alat pembersih perlengkapan ibu menyusui.

h. Cost Stucture. Sama halnya dengann key activities maka penambahan elemen ini ada pada pembelian dan perawatan perlengkapan ibu menyusui. Selain itu juga pada pembiayaan even kompetisi anak.

i. Revenue Stream. Disamping pemasukan utama dari transaksi penyewaan mainan dan perlengkapan ibu menyusui juga ada penambahaan sumber pendapatan yaitu dari pendaftaran event kompetisi balita

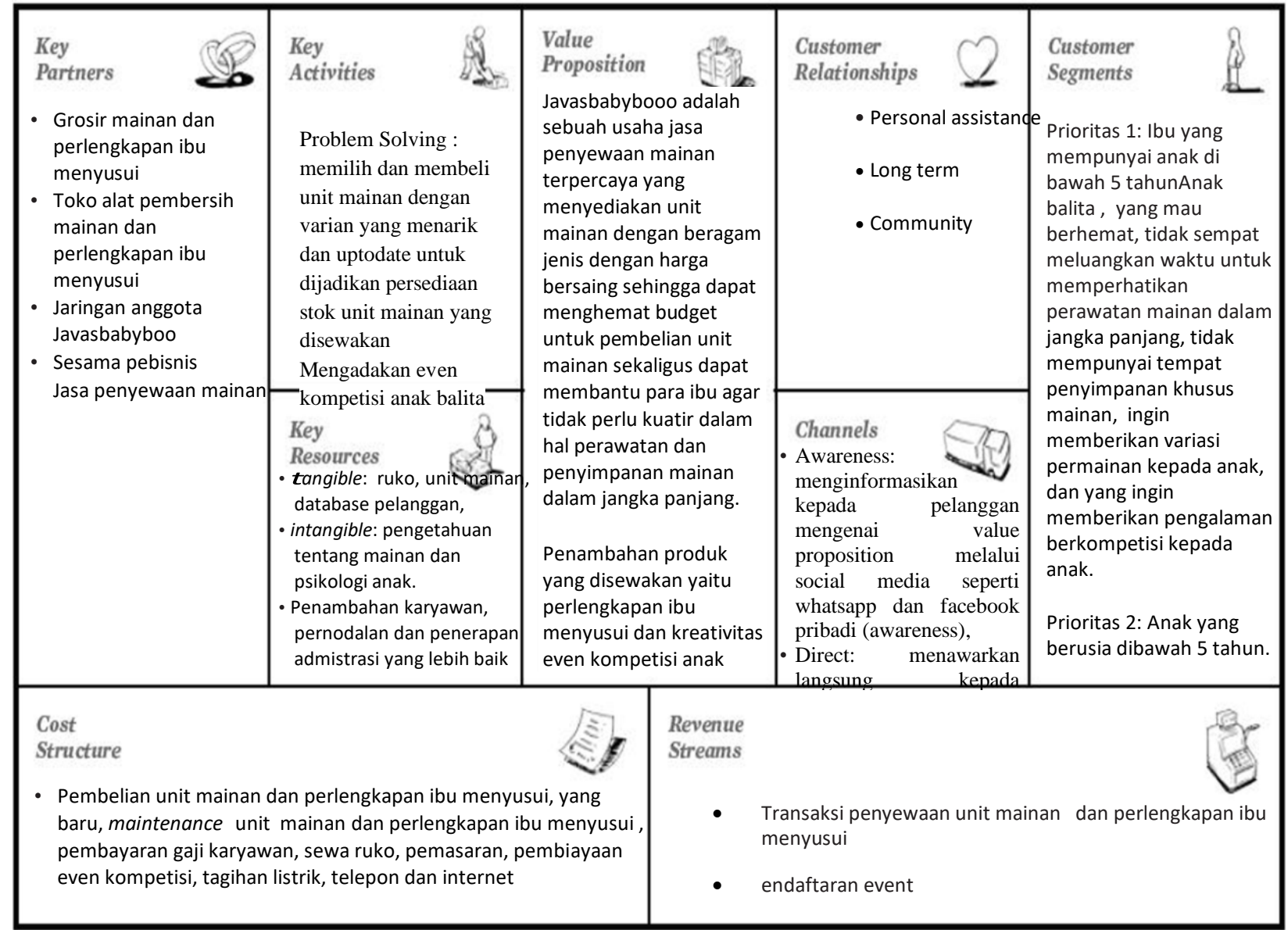

Gambar 2. BMC perbaikan

Sumber: Data yang diolah 2020 
Berdasarkan pemaparan dari hasil penelitian yang telah dilakukan, ternyata sejalan dengan hasil penelitian yang membahas BMC di UKM "Raja Abon Makmur Lestari" Kota Pangkalpinang dimana terdapat perbaikan di hampir semua elemen BMC. Perbaikan ini terfokus pada kegiatan pemasaran dari UKM "Raja Abon Makmur Lestari" Kota Pangkalpinang terutama melalui media pada elemen channel dimana dilakukan maksimasi media online guna meingkatkan pendapatan (Yulia et al., 2020)

\section{KESIMPULAN DAN SARAN}

Berdasarkan hasil analisa yang telah dipaparkan diatas, maka dapat ditarik kesimpulan bahwa BMC yang sedang berjalan pada jasa penyewaan mainan Javasbabyboo sudah cukup baik, hanya perlu ada penambahan di beberapa elemen agar Javasbabyboo dapat lebih berkembang dan memiliki lebih dari satu sumber penghasilan.

Adapun analisis SWOT yang sudah dilakukan menghasilkan solusi dari pemaksimalan kekuatan yaitu dengan menggali informasi mainan yang sedang trending sehingga variasi unit mainan semakin bertambah dan semakin menarik. Sedangkan solusi utama untuk meminimal kekurangan yaitu dengan menambah sumber penghasilan baru misalnya dengan mengadakan even kompetisi permainan anak balita dan menambah produk yang disewakan seperti penyewaan perlengkapan ibu menyusui. Sementara itu, strategi dalam memaksimalkan peluang adalah dengan mendesain ruko semenarik mungkin agar calon pelanggan yang melewati ruko penyewaan mainan tersebut tertarik untuk datang ke ruko mengingat lokasi ruko terletak di tempat yang strategis. Adapun strategi meminimalkan ancaman pada jasa penyewaan Javasbabyboo dari sisi munculnya pesaing dalam bidang usaha yang sejenis dapat dilakukan dengan meningkatkan pelayanan sehingga pelanggan Javasbabybo merasakan kenyamanan.

Berdasarkan analisis dari BMC yang sedang berjalan dan SWOT maka ada penambahan elemen pada BMC perbaikan yang utama yaitu terletak pada value proposition dimana Javasbabyboo disarankan untuk menyewakan perlengkapan ibu menyusui juga dengan alasan harga perlengkapan ibu menyusui lumayan mahal dan digunakan hanya sebentar saja. Selain itu juga disarankan kepada Javasbabyboo untuk menghasilkan produk kreativitas event kompetensi permainan untuk anak=anak agar mereka mempunya pengalaman berkompetensi. Penambahan tersebut tentunya juga akan membuat penyesuaian pada semua elemen kecuali channel.

Adanya BMC perbaikan ini sebagai hasil dari analisa Business Model Canvas Javasbabyboo yang telah peneliti lakukan, diharapkan dapat menaikkan omset sehingga usaha jasa penyewaan mainan dan perlengkapan ibu menyusui Javasbabyboo dapat mengalami kesuksesan dan dapat bertahan lama.

Penelitian ini juga diharapkan dapat digunakan sebagai bahan referensi untuk pengkajian BMC dan analisis SWOT pada penelitian lain dengan obyek dan lokasi yang berbeda sehingga mungkin akan ditemukan strategi-strategi lain yang dapat bermanfaat untuk UMKM di Indonesia.

\section{REFERENSI}

Agustiadi, A., Syarief, R., \& Nurrochmat, D. R. (2018). Strategi Pengembangan Bisnis Rental Mobil Wiralodra 27 dengan Pendekatan Model Bisnis Kanvas. Jurnal Aplikasi Bisnis Dan Manajemen, 4(1), 138-150. https://doi.org/10.17358/jabm.4.1.138

Amalia, D. (2020). 6 Strategi Bisnis untuk Mencapai Keuntungan Maksimal. Jurnal Entrepreneur. https://www.jurnal.id/id/blog/strategi-bisnis-untuk-mencapai-keuntunganmaksimal/ 
Amri, A. (2020). Dampak Covid-19 Terhadap UMKM di Indonesia. Jurnal Brand, 2(1), 147153. https://www.academia.edu/42672824/Dampak_Covid19_Terhadap_UMKM_di_Indonesia

Crotty, Y., Kinney, T., \& Farren, M. (2018). Using the Business Model Canvas (BMC) strategy tool to support the Play4Guidance online entrepreneurial game. International Journal for Transformative Research, 4(1), 34-41. https://doi.org/10.1515/ijtr-2017-0005

Global Leadership Center, T. (2020). Apa Itu Business Model Canvas Dan Mengapa Wajib Digunakan Setiap Pemilik Bisnis? Global Leadership Center. https://glcworld.co.id/penjelasan-business-model-canvas/

Hartatik, ., \& Baroto, T. (2017). Strategi Pengembangan Bisnis Dengan Metode Business Model $\begin{array}{lllll}\text { Canvas. Jurnal Industri, } & \text { Teknik }\end{array}$ https://doi.org/10.22219/jtiumm.vol18.no2.113-120

Hidranto, F. (2020). Dampak Covid-19 Stimulus untuk UMKM. Indonesia.Go.Id. https://indonesia.go.id/narasi/indonesia-dalam-angka/ekonomi/stimulus-untuk-umkm

Jayani, D. H. (2020). Pemerintah Beri Stimulus, Berapa Jumlah UMKM di Indonesia? Kata Data. https://databoks.katadata.co.id/datapublish/2020/04/08/pemerintah-beri-stimulusberapa-jumlah-umkm-di-indonesia

Kotler, P., \& Keller, K. L. (2016). Manajemen Pemasaran edisi 12 Jilid 1. \& 2.Jakarta: PT. Indeks. (12 Jilid 1). PT Index.

LinovHR, A. (2020). Business Model Canvas: Pengertian dan Manfaat Bagi Perusahaan. LinovHR. https://www.linovhr.com/business-model-canvas/

Octobery, R., Abolladaka, J., \& Sundari. (2020). Strategi Usaha Dengan Analisis SWOT Pada Rental Adinda Palangka Raya. Pendidikan Ilmu Pengetahuan Sosial, 2020(12), 49-56. https://e-journal.upr.ac.id/index.php/JP-IPS/article/view/1135

Osterwalder, A., \& Pigneur, Y. (2010). Model Generation. John Wily \& Sons. Inc.

Puspitasari, L. A., Hasun, F., \& Rendra, M. (2019). Evaluasi Model Bisnis Rental Mobil ' Garasi Kampus' Menggunakan Pendekatan Business Model Canvas. Jurnal E-Proceeding of Engineering, 6(2), 6332-6339.

Putri, C. A. (2020). Sedihnya, Omzet UMKM Turun 30\% di Masa Pandemi Covid-19. CNBC Indonesia. https://www.cnbcindonesia.com/news/20201215131853-4-209208/sedihnyaomzet-umkm-turun-30-di-masa-pandemi-covid-19

Rosita, R. (2020). Pengaruh Pandemi Covid-19 Terhadap Umkm Di Indonesia. Jurnal Lentera Bisnis, 9(2), 109. https://doi.org/10.34127/jrlab.v9i2.380

Tabi, A. (2020). Problematika Stay At Home Pada Anak Usia Dini Di Tengah Pandemi Covid 19. Jurnal Golden Age, 4(01), 190-200. https://doi.org/10.29408/jga.v4i01.2244

UKM, H. dan A. H. K. K. dan. (2020). Sektor UMKM Jadi Kunci Pemulihan Ekonomi Di Tengah Pandemi. Kementerian Koperasi Dan Usaha Kecil Dan Menengah Republik Indonesia. http://www.depkop.go.id/read/sektor-umkm-jadi-kunci-pemulihan-ekonomi-ditengah-pandemi

Umar, A., Sasongko, A. H., Aguzman, G., \& Sugiharto. (2018). Business model canvas as a solution for competing strategy of small business in Indonesia. International Journal of Entrepreneurship, 22(1), 1-9.

Winartha, I. M. (2006). Metodelogi Penelitian Sosial Ekonomi. Andi.

Yulia, Y., Bahtera, N. I., Evahelda, E., Hayati, L., \& Bahtera, N. T. (2020). Business Development Strategy Using Business Model Canvas Approach. Jurnal Muara Ilmu Ekonomi Dan Bisnis, 4(1), 106. https://doi.org/10.24912/jmieb.v4i1.7563 